\title{
Partner-Level Factors Associated with Insertive and Receptive Condomless Anal Intercourse among Transgender Women in Lima, Peru
}

\author{
Milan F. Satcher ${ }^{1}$, Eddy R. Segura ${ }^{1}$, Alfonso Silva-Santisteban ${ }^{2}$, Jorge Sanchez ${ }^{3}$, Javier R. \\ Lama $^{3}$, and Jesse L. Clark ${ }^{1}$ \\ ${ }^{1}$ Department of Medicine, Division of Infectious Disease, David Geffen School of Medicine, \\ University of California, Los Angeles, CA, USA \\ ${ }^{2}$ Unit of Health, Sexuality and Human Development, Cayetano Heredia University School of \\ Public Health, Lima, Peru \\ ${ }^{3}$ Asociación Civil Impacta Salud y Educación, Lima, Peru
}

\begin{abstract}
Condomless anal intercourse among transgender women (TW) in Peru has been shown to vary by the type of partner involved (e.g. primary vs. casual vs. transactional sex partner), but no previous studies have explored variations in partner-level patterns of condom use according to type of anal intercourse. We evaluated the relationship between partnership characteristics and condom use during insertive (IAI) versus receptive anal intercourse (RAI) among TW with recent, non-female partners. Condomless IAI was more common with transactional and casual sex partners and by TW who self-reported HIV-uninfected serostatus ( $\mathrm{p}<0.05$ ), alcohol use disorders, or substance use before sex. Condomless RAI was more common with primary partners and by TW who described their HIV serostatus as unknown $(\mathrm{p}<0.05)$. Examining partner-level differences between condomless IAI and RAI reveals distinct patterns of HIV/STI risk among TW, suggesting a need for HIV prevention strategies tailored to the specific contexts of partners, practices, and networks.
\end{abstract}

\section{RESUMEN}

Las investigaciones sobre mujeres trans en Perú han encontrado asociación entre el tipo de pareja y el sexo anal sin condón, pero aún no se han investigado los patrones del uso del condón entre parejas según tipos específicos de sexo anal. Evaluamos la asociación entre las características de las parejas masculinas de mujeres trans y el uso del condón durante sexo anal insertivo y receptivo.

Corresponding author information: Milan F. Satcher, MD MPH, Codman Square Health Center, 637 Washington St, Boston, MA 02124, Phone: 845-728-9348, mfsatcher@gmail.com.

Compliance with Ethical Standards:

Conflict of Interest: Milan Satcher declares that she has no conflict of interest. Eddy Segura declares that he has no conflict of interest. Alfonso Silva-Santisteban declares that he has no conflict of interest. Jorge Sanchez declares that he has no conflict of interest. Javier Lama declares that he has no conflict of interest. Jesse Clark declares that he has no conflict of interest.

Ethical approval: All procedures performed in studies involving human participants were in accordance with the ethical standards of the institutional and/or national research committee and with the 1964 Helsinki declaration and its later amendments or comparable ethical standards.

Informed consent: Informed consent was obtained from all individual participants included in the study. 
El sexo anal insertivo sin condón fue más común con parejas casuales y comerciales, y también entre mujeres trans que reportaron estatus VIH-negativo $(\mathrm{p}<0.05)$, trastornos de uso de alcohol, y uso de alcohol y drogas previos al acto sexual. El sexo anal receptivo sin condón fue más común con parejas estables y entre mujeres trans que no sabían su estatus de VIH ( $<<0.05)$. La investigación diferenciada según uso de condón durante el sexo anal insertivo y receptivo muestra patrones distintos del riesgo de VIH/ITS entre mujeres trans que sugieren la necesidad de desarrollar estrategias distintas de prevención que sean específicas para sus parejas, practicas, redes y contextos sexuales.

\section{Keywords}

Transgender women; HIV; Sexual partnerships; Condomless anal intercourse; Peru

\section{Keywords}

Mujeres trans; VIH; Parejas sexuales; Sexo anal sin condón; Perú

\section{INTRODUCTION}

The HIV epidemic in Peru is disproportionately concentrated among transgender women (TW). TW are individuals who were assigned a male sex at birth and identify along the feminine spectrum of the gender continuum as a female (femenina), woman (mujer), and/or transfeminine (travest $i$ ). HIV prevalence among TW in Peru has been estimated to be as high as $29.6 \%$ [1] and even higher (48.5\%) among Peruvian TW undergoing HIV testing for the first-time [2]. An HIV prevalence of 12-22\% has been described in samples of men who have sex with men (MSM) and MSM/TW combined [3-6] and 0.4\% among the general population [5].

HIV transmission in Peru is largely driven by sexual contact, with one-third of infections believed to occur within primary partnerships [7]. Accordingly, detailed understanding of the factors influencing sexual risk practices in both primary and non-primary partnerships is particularly important. Until recently, most epidemiologic research in Peru examined TW's risk for HIV and sexually transmitted infections (STI) in aggregate with MSM. Studies have described individual-level risk factors for HIV/STIs, including frequency of condomless anal intercourse [7], involvement in transactional sex [8], STI history [9], sexual role [10, 11], substance use history [12, 13], knowledge of partner's HIV serostatus [14], and attendance at MSM/TW venues [15]. In addition to continued research addressing TW as a distinct population, more studies are needed to evaluate how individual risk behaviors are shaped by different partnership contexts.

Assessing how the partnership contexts of TW affect sexual risk behavior is especially important given the unique, multi-level vulnerabilities that increase risk for HIV acquisition among TW. In the absence of laws that recognize and protect individuals with gender nonconforming identities, TW in Peru regularly experience social discrimination, physical violence, and exclusion from education and work opportunities [1, 16]. Such legal and social disenfranchisement increase TW's economic vulnerability and risk of engaging in 
transactional sexual partnerships in order to alleviate financial hardship $[8,17,18]$. The USbased gender affirmation framework for TW of color also posits that gender-based marginalization acts to socially undermine the gender identity of TW and creates a sense of gender-identity threat [19]. According to this framework, TW are more likely to engage in higher-risk sexual behaviors (e.g. transactional sex, receptive anal intercourse, condomless anal intercourse, substance use) in order to cope with and/or satisfy unmet needs for gender affirmation when healthier sources of gender affirmation are inaccessible [17, 19, 20]. An examination of sexual behaviors within specific partnership contexts may therefore help to reveal contexts for sexual transmission of HIV by facilitating the exploration of both partnerand individual-level implications of transphobic social policies and cultural norms.

Previous research in Peru, Brazil, Thailand, and the US has described a greater risk of condomless anal intercourse within the primary partnerships of TW compared to their casual or transactional sex partnerships [1,21-28]. At the same time, qualitative studies with Peruvian and US TW have described a preference for receptive roles during anal intercourse with intimate male partners as a gender-affirming act [11, 19, 20], and described the practice of insertive anal intercourse as something performed predominantly as a transactional sex activity $[11,17,21]$. Building on this understanding of the different motivations for engaging in receptive versus insertive anal intercourse, it is important to consider how condom use varies not only between partnership contexts, but also according to the type of intercourse practiced in distinct partnership contexts. Our analysis is the first in Peru to investigate differences in partner-level patterns of condom use among a sample composed exclusively of TW. Specifically, we assess the association between partner type and condom use during insertive versus receptive anal intercourse with the last three non-female partners of TW in Lima, Peru.

\section{METHODS}

\section{Participants}

We conducted a secondary data analysis of partner-level factors associated with condomless insertive versus receptive anal intercourse among TW in Peru. Data was collected between August 2012 and June 2014 from MSM and TW screened for eligibility for a study of expedited partner therapy and partner notification (EPT/PN) in Lima and Callao, Peru. Participants were directly recruited from community venues by peer recruiters and eligible for inclusion if they were 1) anatomically male at birth, 2) 18 years or older, and 3) reported sexual intercourse (anal or oral) with a male or transfeminine partner in the previous 12 months. Eligibility to participate was determined prior to enrollment. A total of 1,607 men and transgender women were enrolled in the screening study.

In our analysis, we further restricted the sample to participants who: 1) self-identified as transgender and 2) reported anal intercourse with at least one male or transfeminine partner among their last three sexual partnerships. Guided by previous literature on transgender identities in a Peruvian context $[11,16]$, we used participants' responses to an open-response item on sexual identity and a multiple-choice item on sexual orientation/gender identity to restrict the sample to self-identified transgender women (TW). Ambiguous terms provided in the open-response items were reviewed by four different evaluators who collectively 
reached consensus on classification. The following open-response items were recognized as likely part of the Peruvian transfeminine spectrum: travesti, trans, transgenero, transformista, mujer, chica, femenina, proper female names, and variations of these terms.

\section{Procedures}

All participants completed a computer-assisted self interview (CASI) behavioral survey, after which they participated in a physical examination, pre-test counseling, HIV/STI testing, post-test counseling, and syndromic treatment for symptomatic STIs (if present). Participants received 10 Nuevos soles (approximately \$3.50 USD) reimbursement per study visit for their transportation costs, as well as 5 condoms and 5 sachets of lubricant per study visit.

\section{Behavioral Survey}

Participant Characteristics-Participants were asked to identify their age, education level, city, sexual orientation/gender identity, presence of an alcohol use disorder (defined by WHO AUDIT score $>8$ indicating hazardous use, harmful use, or dependent use [29]), history of HIV/STI diagnoses, and number of male or transfeminine sexual partners in the last month. Participants also reported their preferred sexual role, defined as pasiva (preferring strictly receptive anal intercourse), activa (preferring strictly insertive anal intercourse), or moderna (preferring both insertive and receptive anal intercourse).

Characteristics of Last Three Sexual Partners-Data for each of the last three sexual partners were egocentric in nature, meaning that they were based on the reports of the TW participants and not directly reported by the partners themselves. Participants were asked to report characteristics for the last, second to last, and third to last persons with whom they had sex, in chronological order. For each person, the participants reported partnership type as well as their perception of the partner's gender, sexual orientation, sexual role, and HIV status.

Sexual Practices with the Last Three Sexual Partners-Participants were asked to report the sexual practices engaged in during their last sexual encounter with each of their last three sexual partners. Questions with dichotomous categorical responses were used to assess participants' engagement in each of the following sexual practices: insertive anal intercourse, receptive anal intercourse, insertive oral sex, receptive oral sex, and vaginal intercourse. For each practice, participants were asked to specify whether a condom was or was not used. Participants' personal use of alcohol and/or drugs prior to sexual intercourse with each partner was also assessed.

\section{Data Analysis}

Insertive, Receptive, and Overall Condomless Anal Intercourse-The main outcomes were condomless insertive anal intercourse (IAI) and condomless receptive anal intercourse (RAI), which were constructed at the partnership level as dichotomous variables. For each partnership reported by TW, they answered questions on the specific sexual behaviors they engaged in during their last sexual encounter with the partner. Therefore, for each partner, there was data available on a single sexual encounter. From this data, we 
defined the main outcomes as TW practice of (1) condomless IAI and (2) condomless RAI. In our post-hoc analysis, we also created a composite variable for overall condomless anal intercourse (CAI), which reports TW engagement in any condomless anal intercourse, either RAI or IAI, for each partnership reported.

Partner Type-Our main predictor was partner type, which we defined as: 1) "primary", or stable relationships, 2) "casual", which include both casual (unstable) partners and anonymous partners (where the partner's full name or contact information is unknown), and 3) "transactional sex," which includes clients who provided the participant money or goods in exchange for sex and commercial sex providers to whom the participant provided money or goods in exchange for sex.

Other Variables of Interest-Participants' self-described characteristics and reports of each of their partner's gender, sexual orientation, sexual role, and HIV status were also included in the analysis. For each participant, we used their response to the sexual role question and their response to the partner-level anal intercourse variables (insertive, receptive) to constructed a variable for the experience of sexual role strain, which we defined as the practice of a sexual role different from the participant's preferred activa or pasiva sexual role. Sexual role strain will be explored in greater depth in an upcoming paper from our group.

Statistical Methods-We conducted univariate analyses (frequencies, medians) to describe the characteristics of the TW participants and up to three of their most-recent sexual partners. Bivariate tables were constructed to assess the frequencies of condomless IAI and condomless RAI against participant and partner characteristics. Given the correlated nature of the data, we were not able to conduct significance testing in our model selection process due to violation of the chi-square independence assumption. Instead, variables were selected for inclusion in the multivariable models using theoretical reasoning and best subset analysis to select the model with the best fit, as determined by the QIC [30]. We used Poisson regression with robust estimation of standard errors to calculate prevalence ratios (PR) and 95\% confidence intervals (CI) for 1) condomless IAI and 2) condomless RAI in relation to partner type [31]. These multivariable models were constructed under the Generalized Estimating Equation extension with an exchangeable working correlation structure in order to account for the correlation between the last three partners reported by the same participant [32]. A post-hoc analysis repeated these statistical methods to assess the association between overall CAI and partner type in order to determine whether aggregate CAI variables may have masked underlying differences between condomless IAI and condomless RAI. All analyses were conducted in Stata 12.0 (StataCorp, College Town, TX, USA).

All study procedures were approved by the Institutional Review Board of the University of California, Los Angeles and Asociación Civil Impacta Salud y Educación in Lima, Peru. Written informed consent was obtained from all participants prior to their participation in any study procedures. 


\section{RESULTS}

\section{Sample Characteristics}

Of the 150 TW surveyed in the primary study, 138 (92\%) met the inclusion criteria for this analysis (anal intercourse with at least one male or transgender partner during the last three sexual partnerships). Our results are restricted to this analytic sample of $138 \mathrm{TW}$. Detailed demographic and behavioral characteristics of the TW participants are shown in Table 1. Key statistics to note include the self-reported HIV prevalence of $47.1 \%$ and a recent STI prevalence of $48.4 \%$. Almost $40 \%$ of TW reported a history of transactional sex and $65.7 \%$ met the criteria for an alcohol use disorder. The majority (71.0\%) of TW reported a preference for the pasiva (receptive) sexual role, as expected.

\section{Partner Characteristics among the Last Three Sexual Partners of TW}

Table 2 describes the characteristics of TW's partners. Due to the correlated nature of the data, we were unable to conduct significance testing for our bivariate comparisons. TW reported partner characteristics for 376 of their last three sexual partners, with $78.3 \%$ of TW reporting three partners, $15.9 \%$ reporting two partners, and 5.8\% reporting one partner. Thirty-six percent of partners were primary partners, $37.5 \%$ casual, and $26.1 \%$ transactional sex partners. Overall, these partners were predominantly cis-male $(90.7 \%)$ with a preference for the activo sexual role (72.9\%). A high proportion of partners had an unknown HIV status, regardless of partner type.

\section{Sexual Behaviors Engaged During the Last Sexual Encounter with Each of the Last Three Sexual Partners of TW}

Table 3 shows the sexual behaviors practiced by TW during their last sexual encounter with these partners. Due to the correlated nature of the data, we were unable to conduct significance testing for bivariate comparisons. Overall, TW reported using alcohol and drugs prior to $27.7 \%$ and $12.0 \%$, respectively, of the sexual encounters. The prevalence of pre-sex substance use was highest with casual partners (alcohol: 31.9\%; drugs: 17.7\%) and lowest with primary partners (alcohol: 24.1\%; drugs: $8.0 \%$ ).

As anticipated, TW engaged exclusively in RAI within the majority of partnerships (74.7\%) and exclusively in IAI with only $5.4 \%$ of partners. The overall percent of condomless anal sex was $41.2 \%$. Stratified by type of sex, $38.6 \%$ of all RAI encounters were condomless and $41.1 \%$ of all IAI encounters were condomless.

\section{Distribution of Sample and Partner Characteristics by Type of Anal Intercourse}

Table 4 shows the frequencies of the characteristics and sexual behaviors of TW and their partners organized by the type of AI practiced. Again, bivariate significance testing was not conducted due to the correlated nature of the data. Condomless IAI was reported as more prevalent than condomless RAI among TW with: HIV-uninfected status (56.3\% vs. 18.0\%); non-exclusive sexual role, Moderna (45.0\% vs. $19.3 \%)$; sexual role strain (22.2\% vs. $17.2 \%$ ); or use of alcohol in a hazardous (36.8\% vs. $22.0 \%$ ) or harmful way (50.0\% vs. $27.8 \%$ ). Conversely, condomless RAI was more reported than condomless IAI among TW who reported HIV-infected status (27.4\% vs. $18.5 \%)$. 
At the partner-level, TW reported condomless IAI as more prevalent than condomless RAI with partners who were: casual ( $42.4 \%$ vs. $36.6 \%$ ) or transactional ( $54.8 \%$ vs. $32.6 \%$ ); Moderno (55.8\% vs. $38.9 \%$ ); or of an unknown HIV status (50.7\% vs. $42.2 \%)$. The converse was observed for condomless RAI.

\section{Multivariable Analyses of Condomless IAI and RAI among TW}

All multivariable analyses were conducted at the partner-level, at which each partner (and the last sexual episode with this partner) is the unit of analysis. The multivariable analysis of TW's engagement in condomless IAI with their last three partners was adjusted for participants' alcohol use before sex and sexual role. HIV-infected status among TW was significantly associated with a lower prevalence of condomless IAI $\left(\mathrm{PR}_{\mathrm{adj}}=0.55,95 \% \mathrm{CI}\right.$ 0.31-0.96, $\mathrm{p}=0.036$ ), compared to HIV-uninfected TW. Condomless IAI was more prevalent among casual $\left(\mathrm{PR}_{\mathrm{adj}}=1.48,95 \% \mathrm{CI} 0.77-2.84, \mathrm{p}=0.242\right)$ and transactional sex partners $\left(\mathrm{PR}_{\mathrm{adj}}=1.61,95 \% \mathrm{CI} 0.83-3.10, \mathrm{p}=0.156\right)$ than primary partners, though not statistically significant.

The multivariable analysis of TW's engagement in condomless RAI with their last three partners was adjusted for participants' education, HIV status, STI history, alcohol use before sex, sexual role, and partner sexual role. TW with an unknown HIV status had a significantly higher prevalence of condomless RAI than HIV-uninfected TW $\left(\mathrm{PR}_{\mathrm{adj}}=2.30,95 \%\right.$ CI 1.24 $4.29, \mathrm{p}=0.009$ ). TW's condom use practices did not significantly differ by partner type. Having a transactional sex partner was associated with less condomless RAI $\left(\mathrm{PR}_{\mathrm{adj}}=0.70\right.$, 95\% CI 0.43-1.12, $\mathrm{p}=0.139)$ and a trend toward less condomless RAI with casual partners was observed $\left(\mathrm{PR}_{\mathrm{adj}}=0.67,95 \% \mathrm{CI} 0.45-1.00 ; \mathrm{p}=0.05\right)$, compared to having a primary partner.

Post-hoc analysis of TW's engagement in overall condomless CAI revealed a significantly higher prevalence of any CAI among TW with an unknown HIV status $\left(\mathrm{PR}_{\mathrm{adj}}=1.92,95 \%\right.$ CI 1.24-2.96, $\mathrm{p}=0.003$; reference: HIV-uninfected TW) and a trend toward less CAI with casual partners $\left(\mathrm{PR}_{\mathrm{adj}}=0.70,95 \% \mathrm{CI} 0.48-1.04, \mathrm{p}=0.076\right.$; reference: primary partner $)$ when adjusting for the same covariates used in the condomless RAI model. These findings are consistent with those observed for condomless RAI.

\section{DISCUSSION}

Our study examined the relationship between sexual partnership characteristics and the practice of condomless insertive versus receptive anal intercourse among TW in Peru and their non-female partners. To our knowledge, our analysis is the first to examine condom use by Latin American TW during IAI and RAI as separate partner-level outcomes. In our analysis, condomless IAI was more commonly practiced with transactional and casual sex partners and by TW who had a history of harmful or hazardous alcohol use or who had used substances before sex. On the contrary, condomless RAI was more commonly practiced with primary than casual partners and by TW who had a lower reported prevalence of the aforementioned risk factors. Lastly, we found that the self-reported HIV status of TW was significantly associated with their condom use practices during both IAI and RAI, with HIVinfected TW practicing significantly less condomless IAI and TW with an unknown HIV 
status practicing significantly more condomless RAI, compared to the practices of HIVuninfected TW. Situated within a larger social context of systemic marginalization, TW's practice of IAI and RAI may be associated with different motivations and barriers to condom use and differential patterns of HIV/STI risk that necessitate distinct, context-specific strategies for HIV prevention.

The higher prevalence of condomless RAI with primary partners compared to casual and transactional sex partners is consistent with the condom use patterns described among US transfeminine youth and adults [21-23, 25]. These patterns may be explained by TW's perception of the receptive sexual role as gender-affirming [11, 17, 19], an increased sense of intimacy and gender-affirmation during condomless sex with primary partners [17, 19, 21], and perceptions of lower HIV/STI risk in stable partnership contexts [11, 17]. However, research into the male partners of TW in the US has shown that males who partner with TW are more likely to engage in high-risk behaviors, including CAI, compared to males who do not partner with TW $[33,34]$. In Peru, gender expression and sexual roles are typically constructed within a sociocultural context of machismo, homophobia, and transphobia [11]. Therefore, it is also possible that TW may experience limited agency to request or demand condom use against the sexual expectations or preferences of their male primary partners. This may be especially true with insertive male partners, who exercise direct control over condom use and ultimately must consent to wear it. As such, researchers should consider the effectiveness of self-protective biological technologies (e.g. pre-exposure prophylaxis, rectal microbicides, and future neovaginal microbicides) among TW, as well as TW's ability to access such technologies, as potential interventions to increase their control over HIV prevention within primary partnership contexts. Studies of the male partners of TW are also needed in order to better understand the characteristics of these partners, their relationship dynamics with TW, and associated HIV/STI risks. Studies in the US have described a diversity of sexual orientations and risk behaviors among male partners of TW, which have important implications for the risk of HIV/STI transmission between TW and their partners [28, 33, 35]. However, such epidemiological characterizations of HIV/STI risk have yet to be conducted among the partners of TW in Peru. Dyadic studies of TW and their primary partners should be conducted to explore sexual power dynamics and interdependent risks of HIV/STIs, and to inform effective partner-based risk-reduction interventions for this highrisk population. More specifically, researchers should consider exploring partner-level disclosure of HIV serostatus, routine couples testing, partner notification and treatment, sexual role negotiation, and discussion of biological complements to condoms (e.g. preexposure prophylaxis, antiretroviral treatment as prevention) without disrupting the traditional machismo framework for sexual interactions between TW and their male partners.

It is possible that TW's perceptions of primary partnerships as safe, low-risk contexts may also explain our finding that TW who are unaware of their HIV status are significantly more likely to engage in condomless RAI than HIV-uninfected TW. Within such relationships, TW may have a greater trust of their partners and deem HIV testing as unnecessary. Alternatively, such results may reflect a difference in risk consciousness between TW who do and do not know their HIV status. TW who are risk conscious may be more likely to undergo testing and use condoms, while those who are less risk conscious may be less likely 
to pursue testing or use condoms, and perhaps more likely to engage in other high risk behaviors. TW who are unaware of their status may also be ignorant by choice due to a fear of testing positive, a previously described barrier to HIV testing among MSM/TW in Peru [36]. Lastly, these findings may represent an expression of marginalization. TW who are unaware of their HIV status may have lower access to HIV testing due to inadequate access to the formal health care system. TW in Peru have described denial of health care on the basis of their gender identity as well as stigma and discrimination when accessing HIV testing services [16, 37]. US studies have found a higher burden of stigma among TW who do not "pass," or are not perceived by others as female without suspicion or judgment, and a better quality of life among transgender individuals who do pass [19, 38, 39]. Therefore, it is possible that TW in Peru experience disparities in health care access based on whether they have "passing privilege" and legal documents that match their gender presentation, meaning a subgroup may be more likely to receive basic health procedures like HIV tests and the related sexual health knowledge. Future studies should assess the relationship between "passing," access to care, and health literacy among TW and the implications for HIV risk for those unable to access care (e.g. creation of alternative health systems, use of nonmedically approved procedures to enhance passability, needle-sharing during soft-tissue filler injections). Such studies may help to galvanize the revision and creation of systems that are capable of addressing TW in accordance with their gender identity (e.g. government-issued identification with female names, use of female pronouns by healthcare staff, cultural humility in caring for TW clients).

Previous research in Peru has described IAI by TW as a predominantly transactional sex practice requested by clients, for which TW often receive higher compensation $[8,11]$. Consistent with past research, our sample engaged in condomless IAI more often with transactional sex partners than primary partners [11, 25]. Compared to RAI, it is possible that TW have greater individual agency for condom use during IAI, by directly controlling the condom during these practices, and may explain our finding of significantly higher condom use by HIV-infected compared to HIV-uninfected TW. Knowing their infected status, TW engaging in IAI may assert the use of condoms in order to prevent transmitting the infection to their partner. However, condomless IAI may be more commonly practiced by HIV-uninfected TW and with transactional partners due to systemic marginalization, whereby social and structural exclusion increases TW's risk of unemployment (regardless of their educational attainment), poverty, practice of sex work as a main economic activity, and engagement in associated high-risk social contexts (e.g. substance use, violence) [16, 40]. Within these contexts, TW may yield to client demands for condomless IAI. Such an argument is supported by our findings of a higher prevalence of alcohol use disorders, substance use before sex, and sexual role strain (performing a sexual role that differs with one's preferred sexual role) among TW practicing condomless IAI, compared to those practicing condomless RAI. Outside of transactional sex partnerships, HIV-uninfected TW may engage in condomless IAI in their primary or casual partnerships if they are aware that IAI is associated with less risk of acquiring HIV [41], and therefore perceive themselves as at low risk of acquiring HIV as the insertive partner.

Accordingly, researchers should explore the use of HIV prevention technologies that lack economic value within a sex work context and can be independently accessed and controlled 
by TW (e.g. antiretroviral treatment as prevention, pre-exposure prophylaxis, topical penile microbicides). Further, it is imperative that the study of such technologies are wellintegrated into multi-level, rights-based interventions that target the social and structural drivers of marginalization (e.g. lack of legal recognition of gender non-conforming identities, non-discrimination laws, medical training in gender-affirming care) in order to decrease TW's experience of the downstream social, economic, and psychological pressures to engage in high risk behaviors, as well as to ensure that health systems are accessible and equipped to provide such technologies to TW within the context of affirming, nondiscriminatory care.

Condom use patterns for RAI in our sample paralleled previous findings of a higher prevalence of overall CAI within the primary partnerships of MSM and TW in Peru [1, 27] and TW in the US [24, 26, 28, 42]. The approximation of condomless RAI to overall CAI in our analysis raises concerns that factors associated with composite CAI may be driven by our sample's predominant sexual behavior (RAI) and therefore may mask important distinctions between specific sexual behaviors. Such was demonstrated by the different condom use patterns for IAI in our sample. Studies among MSM have similarly described distinct risk patterns for condomless IAI versus condomless RAI, indicating that separate analyses are also relevant in other populations that engage in anal intercourse [43]. Examining composite CAI may be especially inappropriate for TW due to the aforementioned social and gendered meanings attached to specific sexual roles. Future studies of MSM and TW in Peru should analyze sexual behaviors separately in order to characterize high-risk subgroups, identify the specific sexual contexts within which HIV/STI vulnerabilities are experienced, and inform interventions that promote behavior-based risk reduction strategies.

Our analysis has several limitations. As a secondary analysis, the available data was limited by the original study intentions, which were to screen MSM and TW in order to determine STI status and eligibility to participate in a partner notification and expedited partner therapy study. Due to the emphasis on recruiting participants with notifiable sexual partners, it is possible that TW who engaged in sex work and other high-risk contexts are underrepresented in our sample. In addition, the screening survey did not evaluate social factors like participant employment, economic position, housing status, or mental health, nor any partner demographics, which could have helped to further define high-risk TW subgroups. The original study was also not powered to detect differences in condomless IAI and condomless RAI among TW and the statistical trends suggest that we may have been underpowered to detect underlying associations. Furthermore, TW participants provided partner characteristics rather than direct measurement from the partners, which raises a concern for the reliability of our partner-related data. Some of our TW participants also reported their partners non-chronologically, which may be a reflection of recall bias or reporting of their most significant last three relationships. Therefore, the results of this study may not fully reflect the most recent sexual partnerships of our TW sample. Lastly, our findings and their implications are only applicable to TW with non-female partners living in Lima, Peru. Future studies should aim to recruit larger samples of TW and contribute to a growing body of TW-specific literature in Peru. Such studies should ground their questions 
in time (e.g. (a) When was the last time you had sex? (b) With whom did you have sex? etc.) in order to improve the accuracy of reporting.

Studies should also aim to directly evaluate the characteristics of TW's partners and include questions on partner demographics, relationship duration, and sexual concurrency.

Our analysis provides insights into the complexity and diversity of sexual behaviors among TW, as well as the influence of partnership formations and social contexts on sexual risk for HIV, issues which would not have been fully captured through an analysis of aggregated sexual behaviors. The findings raise important interdisciplinary questions on the relationship between cultural constraints on gender and sexual roles, and the sexual risks enacted within distinct partnership contexts, as positioned within a larger socio-legal milieu of transgender marginalization. Multicomponent, rights-based interventions that target the individual, partnership, community and structural levels are needed in order to decrease social vulnerability, improve access to positive gender-affirming experiences and healthy coping resources, promote communicative and equal partnership dynamics, and provide flexible HIV prevention technologies that can accommodate the multiple sexual contexts of risk among TW.

\section{Acknowledgments}

We would like to express gratitude to the study participants, peer recruiters, and staff of the Asociación Civil Impacta Salud y Educación, particularly Jessica Rios, for their contributions to this study. Without their involvement, this study would not have been possible. Milan F. Satcher received funding from the UCLA South American Program in HIV Prevention Research (SAPHIR; NIH R25 MH087222). The primary research for this secondary data analysis was funded by the NIH/NIMH (NIH R21 MH092232 and K23 MH084611).

\section{REFERENCES}

1. Silva-Santisteban A, Raymond H, Salazar X, et al. Understanding the HIV/AIDS epidemic in transgender women of Lima, Peru: results from a sero-epidemiologic study using respondent driven sampling. AIDS Behav. 2012; 16:872-881. [PubMed: 21983694]

2. Lipsitz MC, Segura ER, Castro JL, et al. Bringing testing to the people - benefits of mobile unit HIV/syphilis testing in Lima, Peru, 2007-2009. Int J STD AIDS. 2014 Apr; 25(5):325-331. [PubMed: 24108451]

3. Sanchez J, Lama JR, Kusunoki L, et al. HIV-1, sexually transmitted infections, and sexual behavior trends among men who have sex with men in Lima, Peru. J Acquir Immune Defic Syndr. 2007 Apr 15; 44(5):578-585. [PubMed: 17279049]

4. MINSA. National report on progress achieved in the country Peru. Lima, Peru: Ministry of Health, Joint United Nations Program on HIV/AIDS; 2012.

5. UNAIDS. Global report: UNAIDS report on the global AIDS epidemic. 2013. [Internet]. Available from: http://www.unaids.org/en/resources/campaigns/globalreport2013/globalreport

6. Perez-Brumer AG, Konda KA, Salvatierra HJ, et al. Prevalence of HIV, STIs, and Risk Behaviors in a Cross-Sectional Community- and Clinic-Based Sample of Men Who Have Sex with Men (MSM) in Lima, Peru. PLoS ONE. 2013 Apr 25.8(4)

7. Goodreau SM, Carnegie NB, Vittinghoff E, et al. What drives the US and Peruvian HIV epidemics in men who have sex with men (MSM)? PloS ONE. 2012; 7(11):e50522. [PubMed: 23209768]

8. Nureña CR, Zúñiga M, Zunt J, Mejía C, Montano S, Sánchez JL. Diversity of commercial sex among men and male-born trans people in three Peruvian cities. Cult Health Sex. 2011 Nov; 13(10): 1207-1221. [PubMed: 21936651] 
9. Lama JR, Lucchetti A, Suarez L, et al. Association of herpes simplex virus type 2 infection and syphilis with human immunodeficiency virus infection among men who have sex with men in Peru. J Infect Dis. 2006 Nov 15; 194(10):1459-1466. [PubMed: 17054077]

10. Goodreau SM, Goicochea LP, Sanchez J. Sexual role and transmission of HIV Type 1 among men who have sex with men, in Peru. J Infect Dis. 2005 Feb 1.(191 Suppl 1):S147-S158. [PubMed: 15627225]

11. Clark J, Salvatierra J, Segura E, et al. Moderno love: sexual role-based identities and HIV/STI prevention among men who have sex with men in Lima, Peru. AIDS Behav. 2013 May; 17(4): 1313-1328. [PubMed: 22614747]

12. Deiss RG, Clark JL, Konda KA, et al. Problem drinking is associated with increased prevalence of sexual risk behaviors among men who have sex with men (MSM) in Lima, Peru. Drug Alcohol Depend. 2013 Sep 1; 132(1-2):134-139. [PubMed: 23434130]

13. Ludford KT, Vagenas P, Lama JR, et al. Screening for drug and alcohol use disorders and their association with HIV-related sexual risk behaviors among men who have sex with men in Peru. PloS ONE. 2013; 8(8):e69966. [PubMed: 23936364]

14. Nagaraj S, Segura ER, Peinado J, et al. A cross-sectional study of knowledge of sex partner serostatus among high-risk Peruvian men who have sex with men and transgender women: implications for HIV prevention. BMC Public Health. 2013; 13:181. [PubMed: 23448153]

15. Verre M, Peinado J, Segura ER, et al. Socialization Patterns and Their Associations with Unprotected Anal Intercourse, HIV, and Syphilis Among High-Risk Men Who Have Sex with Men and Transgender Women in Peru. AIDS Behav. 2014 Oct; 18(10):2030-2039. [PubMed: 24788782]

16. Salazar X, Villayzán J, Silva-Santisteban A, Caceres C. Las personas trans y la epidemia del VIH/ SIDA en el Perú. 2010 IESSDEH, UPCH, ONUSIDA, amfAR.

17. Bockting WO, Robinson BE, Rosser BR. Transgender HIV prevention: a qualitative needs assessment. AIDS Care. 1998 Aug; 10(4):505-525. [PubMed: 9828969]

18. Bianchi FT, Reisen CA, Zea MC, et al. Sex work among men who have sex with men and transgender women in Bogotá. Arch Sex Behav. 2014 Nov; 43(8):1637-1650. [PubMed: 24464550]

19. Sevelius JM. Gender Affirmation: A Framework for Conceptualizing Risk Behavior among Transgender Women of Color. Sex Roles. 2013 Jun 1; 68(11-12):675-689. [PubMed: 23729971]

20. Melendez RM, Pinto R. "It"s really a hard life': Love, gender and HIV risk among male-to-female transgender persons. Cult Health Sex. 2007; 9(3):233-245. [PubMed: 17457728]

21. Nemoto T, Operario D, Keatley J, Villegas D. Social context of HIV risk behaviours among maleto-female transgenders of colour. AIDS Care. 2004 Aug; 16(6):724-735. [PubMed: 15370060]

22. Wilson EC, Garofalo R, Harris DR, Belzer M. Sexual Risk Taking Among Transgender Male-toFemale Youths With Different Partner Types. Am J Public Health. 2010 Aug; 100(8):1500-1505. [PubMed: 20622176]

23. Bowers JR, Branson CM, Fletcher JB, Reback CJ. Predictors of HIV Sexual Risk Behavior among Men Who Have Sex with Men, Men Who Have Sex with Men and Women, and Transgender Women. Int J Sex Health Off J World Assoc Sex Health. 2012; 24(4):290-302.

24. Martins TA, Kerr LRFS, Macena RHM, et al. Travestis, an unexplored population at risk of HIV in a large metropolis of northeast Brazil: a respondent-driven sampling survey. AIDS Care. 2013; 25(5):606-612. [PubMed: 23082818]

25. Nemoto T, Bödeker B, Iwamoto M, Sakata M. Practices of receptive and insertive anal sex among transgender women in relation to partner types, sociocultural factors, and background variables. AIDS Care. 2014 Apr; 26(4):434-440. [PubMed: 24160715]

26. Wilson EC, Santos G-M, Raymond HF. Sexual mixing and the risk environment of sexually active transgender women: data from a respondent-driven sampling study of HIV risk among transwomen in San Francisco, 2010. BMC Infect Dis. 2014; 14:430. [PubMed: 25100405]

27. Cambou MC, Perez-Brumer AG, Segura ER, et al. The risk of stable partnerships: associations between partnership characteristics and unprotected anal intercourse among men who have sex with men and transgender women recently diagnosed with HIV and/or STI in Lima, Peru. PloS ONE. 2014; 9(7):e102894. [PubMed: 25029514] 
28. Reisner SL, Vetters R, White JM, et al. Laboratory-confirmed HIV and sexually transmitted infection seropositivity and risk behavior among sexually active transgender patients at an adolescent and young adult urban community health center. AIDS Care. 2015 Mar 19; 27(8): 1031-1036. [PubMed: 25790139]

29. Babor T, Higgins-Biddle JC, Saunders JB, Monteiro MG. The Alcohol Use Disorders Identification Test (AUDIT): Guidelines for Use in Primary Care. World Health Organization. 2001

30. Cui J. QIC program and model selection in GEE analyses. Stata Journal. 2007; 7(2):209-220.

31. Barros AJD, Hirakata VN. Alternatives for logistic regression in cross-sectional studies: an empirical comparison of models that directly estimate the prevalence ratio. BMC Med Res Methodol. 2003 Oct 20.3:21. [PubMed: 14567763]

32. Hanley JA, Negassa A, Edwardes MDdeB, Forrester JE. Statistical Analysis of Correlated Data Using Generalized Estimating Equations: An Orientation. Am J Epidemiol. 2003 Feb 15; 157(4): 364-375. [PubMed: 12578807]

33. Bockting W, Miner M, Rosser BRS. Latino men's sexual behavior with transgender persons. Arch Sex Behav. 2007 Dec; 36(6):778-786. [PubMed: 17333327]

34. Reisner S, Mimiaga M, Bland SE, Driscoll MA, Cranston K, Mayer KH. Pathways to embodiment of HIV risk: black men who have sex with transgender partners, Boston, Massachusetts. AIDS Educ Prev Off Publ Int Soc AIDS Educ. 2012 Feb; 24(1):15-26.

35. Operario D, Nemoto T, Iwamoto M, Moore T. Unprotected sexual behavior and HIV risk in the context of primary partnerships for transgender women. AIDS Behav. 2011 Apr; 15(3):674-682. [PubMed: 20740376]

36. Blas MM, Alva IE, Cabello R, Carcamo C, Kurth AE. Risk Behaviors and Reasons for not Getting Tested for HIV among Men Who Have Sex with Men: An Online Survey in Peru. PLoS ONE. 2011 Nov 9.6(11):e27334. [PubMed: 22096551]

37. Silva-Santisteban A, Segura E, Sandoval C, Girón M, Petrera M, Caceres C. Determinants of unequal HIV care access among people living with HIV in Peru. Glob Health. 2013 May 17.9:22.

38. Ainsworth TA, Spiegel JH. Quality of life of individuals with and without facial feminization surgery or gender reassignment surgery. Qual Life Res Int J Qual Life Asp Treat Care Rehabil. 2010 Sep; 19(7):1019-1024.

39. Gerhardstein KR, Anderson VN. There's More Than Meets the Eye: Facial Appearance and Evaluations of Transsexual People. Sex Roles. 2010 Jan 30; 62(5-6):361-373.

40. Poteat T, Wirtz AL, Radix A, et al. HIV risk and preventive interventions in transgender women sex workers. The Lancet. 2015 Jan 17; 385(9964):274-286.

41. Patel P, Borkowf CB, Brooks JT, Lasry A, Lansky A, Mermin J. Estimating per-act HIV transmission risk: a systematic review. AIDS Lond Engl. 2014 Jun 19; 28(10):1509-1519.

42. Nemoto T, Iwamoto M, Perngparn U, Areesantichai C, Kamitani E, Sakata M. HIV-related risk behaviors among kathoey (male-to-female transgender) sex workers in Bangkok, Thailand. AIDS Care. 2012 Feb 1; 24(2):210-219. [PubMed: 21780964]

43. Jin F, Prestage GP, Mao L, et al. "Any Condomless Anal Intercourse" is No Longer an Accurate Measure of HIV Sexual risk Behavior in Gay and Other Men Who have Sex with Men. Front Immunol. 2015; 6:86. [PubMed: 25774158] 


\section{Table 1}

Characteristics of TW Participants in Lima, Peru, 2012-2014; N=138*

\begin{tabular}{|c|c|}
\hline Participant-Level Characteristics & n $(\%)$ \\
\hline Age in years median (IQR) & $27(22-33)$ \\
\hline \multicolumn{2}{|l|}{ Education } \\
\hline Less than Secondary & $46(33.6)$ \\
\hline Secondary Complete & $53(38.7)$ \\
\hline University/Technical School & $38(27.4)$ \\
\hline \multicolumn{2}{|l|}{ City } \\
\hline Lima & $101(73.7)$ \\
\hline Callao & $36(26.3)$ \\
\hline \multicolumn{2}{|l|}{ HIV Status ${ }^{a}$} \\
\hline Infected & $65(47.1)$ \\
\hline Uninfected & $63(45.7)$ \\
\hline Unknown & $10(7.2)$ \\
\hline \multicolumn{2}{|l|}{ Recent and Persistent STIs $b$} \\
\hline Yes & $62(48.4)$ \\
\hline No & $61(47.7)$ \\
\hline Unsure & $5(3.9)$ \\
\hline \multicolumn{2}{|l|}{ Sexual Orientation/Gender Identity $c$} \\
\hline Heterosexual & $3(2.2)$ \\
\hline Bisexual & $3(2.2)$ \\
\hline Homosexual & $61(44.2)$ \\
\hline Transgender & $63(44.6)$ \\
\hline Other & $2(1.4)$ \\
\hline Don't Know & $6(4.4)$ \\
\hline \multicolumn{2}{|l|}{ Alcohol Use Disorders (AUD) ${ }^{d}$} \\
\hline No AUD or Social Drinker & $47(34.3)$ \\
\hline Hazardous Use & $51(37.2)$ \\
\hline Harmful Use & $20(14.6)$ \\
\hline Dependence Use & $19(13.9)$ \\
\hline \multicolumn{2}{|l|}{ Sexual Role } \\
\hline Activa (Insertive) & $6(4.4)$ \\
\hline Pasiva (Receptive) & $98(71.0)$ \\
\hline Moderna (Versatile) & $34(24.6)$ \\
\hline \multicolumn{2}{|l|}{ Male/Transgender Sex Partners in } \\
\hline Last Month median (IQR) & $10(2-28)$ \\
\hline \multicolumn{2}{|l|}{ Type of Partnerships Engaged ${ }^{e}$} \\
\hline Primary & $70(50.7)$ \\
\hline Casual & $69(50.0)$ \\
\hline Anonymous & $14(10.1)$ \\
\hline
\end{tabular}




\begin{tabular}{ll}
\hline Participant-Level Characteristics & $\mathbf{n}(\boldsymbol{\%})$ \\
\hline Transactional Sex Client & $45(32.6)$ \\
Transactional Sex Provider & $5(3.6)$ \\
Transactional Sex Activity $f$ & \\
Yes & $55(39.8)$ \\
No & $83(60.1)$ \\
Type of Anal Intercourse Practiced & \\
Exclusively Insertive & $5(3.6)$ \\
Exclusively Receptive & $90(65.2)$ \\
Both Insertive and Receptive & $43(31.2)$ \\
Sexual Role Strain $g$ & \\
Yes & $30(21.7)$ \\
No & $74(53.6)$ \\
Moderna & $34(24.6)$ \\
Condomless Anal Intercourse $(\mathrm{CAI})$ & \\
Overall Condomless Insertive AI ${ }^{h}$ & $24(50.0)$ \\
Overall Condomless Receptive AI ${ }^{i}$ & $72(54.1)$ \\
Condomlessness for Any AI $j$ & $80(58.0)$ \\
\hline
\end{tabular}

* Discrepancies in total values for some variables are due to missing data

${ }^{a}$ Self-reported

${ }^{b}$ Reported receiving diagnosis within last 30 days of at least one bacterial STI or ever diagnosed with a viral STI. STIs included: syphilis, gonorrhea, chlamydia, genital ulcers, genital herpes, genital warts, urethritis, proctitis, UTI.

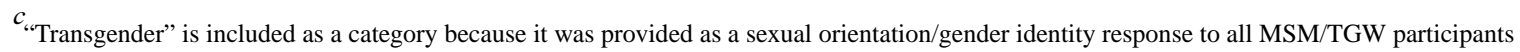
completing the screening survey.

${ }^{d}$ Categories based on internationally-validated WHO AUDIT guidelines [29].

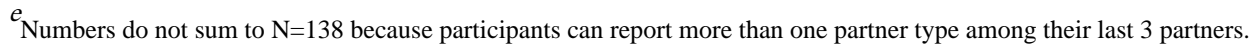

$f_{\text {In last month and among last } 3 \text { sexual partners }}$

$g_{\text {Strain }}$ practicing a type of AI that does not match the preferred activa/pasiva role. No strain = practicing the type of AI that matches the preferred activa/pasiva role.

$h_{\text {Percent based on the total number of transwomen engaging in insertive AI }(\mathrm{N}=48)}$

${ }^{i}$ Percent based on the total number of transwomen engaging in receptive AI $(\mathrm{N}=133)$

$j_{\text {Percent based on the total number of transwomen in sample ( } \mathrm{N}=138)}$ 
Table 2

Characteristics of Last 3 Non-Female Sexual Partners of TW in Lima, Peru, 2012-2014; N=376*

\begin{tabular}{|c|c|c|c|c|}
\hline Partner-Level Characteristics $a$ & $\begin{array}{l}\text { Total Partners } \\
\qquad \begin{array}{c}\text { N=376 } \\
\text { n }(\%)\end{array}\end{array}$ & $\begin{array}{c}\text { Primary } \\
\begin{array}{c}\mathrm{N}=137(36.4 \%) \\
\mathrm{n}(\%)\end{array}\end{array}$ & $\begin{array}{c}\frac{\text { Casual } b}{\mathrm{~N}=141(37.5 \%)} \\
\mathrm{n}(\%)\end{array}$ & $\begin{array}{l}\frac{\text { Transactional }}{\underline{\text { Sex }} c} \\
\begin{array}{c}\mathrm{N}=98(26.1 \%) \\
\mathrm{n}(\%)\end{array}\end{array}$ \\
\hline \multicolumn{5}{|l|}{ Partner Type } \\
\hline Primary & $137(36.4)$ & & & \\
\hline Casual & $125(33.2)$ & - & - & - \\
\hline Anonymous & $16(4.3)$ & & & \\
\hline Transactional Sex Client & $89(23.7)$ & & & \\
\hline Transactional Sex Worker & $9(2.4)$ & & & \\
\hline \multicolumn{5}{|l|}{ Gender } \\
\hline Men & $341(90.7)$ & $125(91.2)$ & $136(96.4)$ & $80(81.6)$ \\
\hline Transgender & $25(9.3)$ & $12(9.8)$ & $5(3.6)$ & $28(18.4)$ \\
\hline \multicolumn{5}{|l|}{ Perceived Sexual Orientation/ } \\
\hline \multicolumn{5}{|l|}{ Gender Identity of Partner } \\
\hline Heterosexual & $126(33.5)$ & $40(29.2)$ & $55(39.0)$ & $31(31.6)$ \\
\hline Bisexual & $165(43.9)$ & $69(50.4)$ & $58(41.1)$ & $38(38.8)$ \\
\hline Homosexual & $44(11.7)$ & $18(13.1)$ & $15(10.6)$ & $11(11.2)$ \\
\hline Transgender & $9(2.4)$ & $1(0.7)$ & $2(1.4)$ & $6(6.1)$ \\
\hline Other $^{d}$ & $15(4.0)$ & $2(1.5)$ & $5(3.5)$ & $8(8.2)$ \\
\hline Don't Know & $17(4.5)$ & $7(5.1)$ & $6(4.3)$ & $4(4.1)$ \\
\hline \multicolumn{5}{|l|}{ Sexual Role } \\
\hline Activo & $274(72.9)$ & $115(83.9)$ & $107(75.9)$ & $52(53.1)$ \\
\hline Pasivo & $26(6.9)$ & $11(8.0)$ & $4(2.8)$ & $11(11.2)$ \\
\hline Moderno & $65(17.3)$ & $10(7.3)$ & $23(16.3)$ & $32(32.6)$ \\
\hline Other ${ }^{e}$ & $2(0.5)$ & $0(0.0)$ & $1(0.7)$ & $1(1.0)$ \\
\hline Don't Know & $9(2.4)$ & $1(0.7)$ & $6(4.3)$ & $2(2.0)$ \\
\hline \multicolumn{5}{|l|}{ HIV Status } \\
\hline Infected & $23(6.1)$ & $17(12.4)$ & $4(2.8)$ & $2(2.0)$ \\
\hline Uninfected & $58(15.4)$ & 31 (22.6) & $22(15.6)$ & $5(5.1)$ \\
\hline Unknown & $295(78.5)$ & $89(65.0)$ & 115 (81.6) & 91 (92.9) \\
\hline
\end{tabular}

Discrepancies in total values for some variables are due to missing data.

${ }^{a}$ As perceived and reported by TW participants

$b_{\text {Includes anonymous partners }(\mathrm{n}=16)}$

$c_{\text {Includes Transactional sex clients and providers }}$

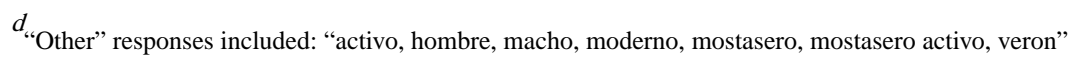

e"Other" qualitative responses included: "macho, bisexual" 
Table 3

Sexual Practices of TW with their Last 3 Non-Female Sexual Partners of TW in Lima, Peru, 2012-2014; $\mathrm{N}=376^{*}$

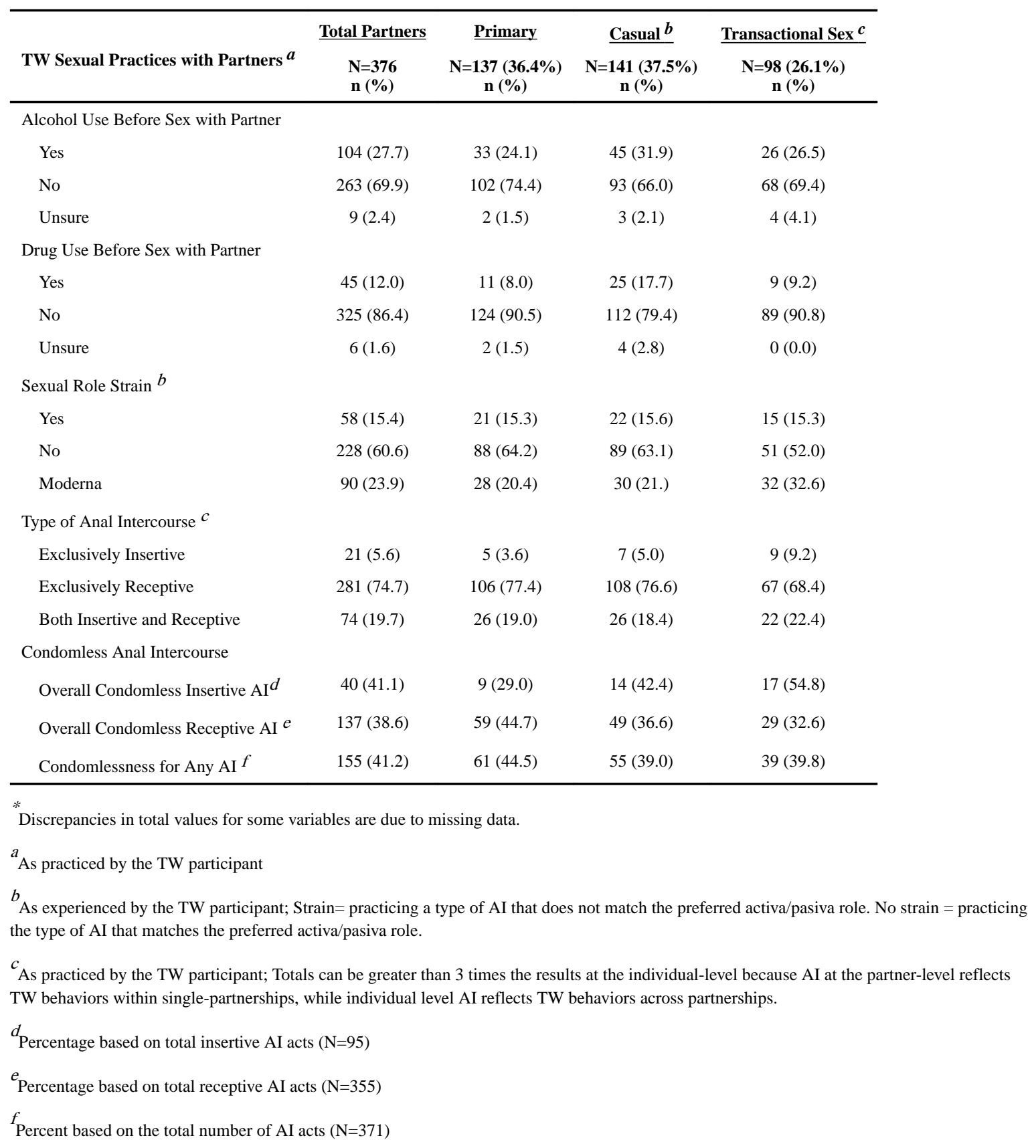




\section{Table 4}

Participant and Partner Characteristics and Condomless Anal Intercourse with the Last Three Non-Female Sexual Partners of TW, Lima, Peru, 2012-2014

\begin{tabular}{|c|c|c|}
\hline \multirow{2}{*}{ Participant-Level Characteristics } & \multirow{2}{*}{$\frac{\text { Insertive AI }(\mathbf{N}=48)^{\dagger}}{\text { Condomless }(\mathrm{N}=15)^{*}}$} & \multirow{2}{*}{$\frac{\text { Receptive AI }(\mathrm{N}=133)^{\dagger}}{\text { Condomless }(\mathrm{N}=\mathbf{3 2})^{*}}$} \\
\hline & & \\
\hline Age median (IQR) & $28(22-34)$ & $27.5(22.5-31.5)$ \\
\hline \multicolumn{3}{|l|}{ Education } \\
\hline Less than Secondary & $8(36.4)$ & $11(25.6)$ \\
\hline Secondary & $3(20.0)$ & $12(23.1)$ \\
\hline University/Technical School & $4(36.4)$ & $9(24.3)$ \\
\hline \multicolumn{3}{|l|}{ HIV Status ${ }^{a}$} \\
\hline Infected & $5(18.5)$ & $17(27.4)$ \\
\hline Uninfected & $9(56.3)$ & $11(18.0)$ \\
\hline Unknown & $1(20.0)$ & $4(40.0)$ \\
\hline \multicolumn{3}{|l|}{ Recent STIs $b$} \\
\hline Yes & $8(30.8)$ & $15(25.9)$ \\
\hline No & $5(31.3)$ & $13(21.7)$ \\
\hline Unsure & $1(25.0)$ & $1(20.0)$ \\
\hline \multicolumn{3}{|l|}{ Sexual Role } \\
\hline Activa & $0(0.0)$ & $0(0.0)$ \\
\hline Pasiva & $6(24.0)$ & $26(26.8)$ \\
\hline Moderna & $9(45.0)$ & $6(19.3)$ \\
\hline \multicolumn{3}{|l|}{ Sexual Role Strain $c$} \\
\hline Yes & $6(22.2)$ & $5(17.2)$ \\
\hline No & $0(0.0)$ & $21(28.8)$ \\
\hline \multicolumn{3}{|l|}{ Alcohol Use Disorders (AUD) ${ }^{d}$} \\
\hline No AUD & $4(26.7)$ & $12(25.5)$ \\
\hline Hazardous Use & $7(36.8)$ & $11(22.0)$ \\
\hline Harmful Use & $2(50.0)$ & $5(27.8)$ \\
\hline Dependent Use & $2(20.0)$ & $4(23.5)$ \\
\hline \multirow{2}{*}{$\begin{array}{l}\text { Partner-Level Characteristics and } \\
\text { TW Sexual Practices } e\end{array}$} & Insertive $\mathrm{AI}(\mathrm{N}=95)^{t}$ & Receptive AI $(\mathrm{N}=355)^{*}$ \\
\hline & Condomless $(\mathrm{N}=40)^{*}$ & Condomless $(\mathrm{N}=137)^{*}$ \\
\hline
\end{tabular}

$\begin{array}{lcc}\text { Partner Type } & 9(29.0) & 59(44.7) \\ \text { Primary } & 14(42.4) & 49(36.6) \\ \text { Casual } & 17(54.8) & 29(32.6) \\ \text { Transactional Sex } & & \\ \text { Gender } & 33(43.4) & 127(39.3) \\ \text { Men } & 7(36.8) & 10(31.2) \\ \text { Transgender } & & \end{array}$

Sexual Orientation/Gender Identity 


\begin{tabular}{|c|c|c|}
\hline \multirow{2}{*}{ Participant-Level Characteristics } & \multirow{2}{*}{$\frac{\underline{\text { Insertive AI }(\mathrm{N}=48)^{\dagger}}}{\text { Condomless }(\mathrm{N}=15)^{*}}$} & \multirow{2}{*}{$\frac{\text { Receptive AI }(\mathrm{N}=\mathbf{1 3 3})^{\prime}}{\text { Condomless }(\mathrm{N}=32)^{*}}$} \\
\hline & & \\
\hline Heterosexual & $3(16.7)$ & $45(36.0)$ \\
\hline Bisexual & $17(53.1)$ & $65(40.9)$ \\
\hline Homosexual & $6(25.0)$ & $11(30.6)$ \\
\hline Transgender $f$ & $2(50.0)$ & $4(44.4)$ \\
\hline Other & $8(88.9)$ & $5(45.4)$ \\
\hline \multicolumn{3}{|l|}{ Sexual Role } \\
\hline Activo & $11(32.3)$ & $108(39.7)$ \\
\hline Pasivo & $3(21.4)$ & $6(31.6)$ \\
\hline Moderno & $24(55.8)$ & $21(38.9)$ \\
\hline Other $g$ & $0(0.0)$ & $1(50.0)$ \\
\hline \multicolumn{3}{|l|}{ HIV Status } \\
\hline Infected & $2(16.7)$ & $7(30.4)$ \\
\hline Uninfected & $1(10.0)$ & $13(23.6)$ \\
\hline Unknown & $37(50.7)$ & $117(42.2)$ \\
\hline \multicolumn{3}{|l|}{ Participant Alcohol Use Before Sex } \\
\hline Yes & $18(50.0)$ & $46(47.9)$ \\
\hline No & $22(38.6)$ & $88(35.2)$ \\
\hline Unsure & $0(0.0)$ & $3(33.3)$ \\
\hline \multicolumn{3}{|l|}{ Participant Drugs Use Before Sex } \\
\hline Yes & $9(42.9)$ & $119(38.6)$ \\
\hline No & $30(41.7)$ & $17(41.5)$ \\
\hline Unsure & $1(50.0)$ & $1(16.7)$ \\
\hline
\end{tabular}

Figures for condom-protected AI not shown, as they are the complement of the condomless AI figures.

${ }^{t} \mathrm{~N}$ denotes total number of participants engaging in type of AI.

${ }^{t} \mathrm{~N}$ denotes total number of partners with which TW engage in type of AI.

${ }^{a}$ Self-reported

$b_{\mathrm{Re}}$ gonorrhea, chlamydia, genital ulcers, genital herpes, genital warts, urethritis, proctitis, UTI.

${ }^{c}$ Restricted to activa/pasiva-identified TW (n=104). Strain= practicing a type of AI that does not match the preferred activa/pasiva role. No strain $=$ practicing the type of AI that matches the preferred activa/pasiva role.

${ }^{d}$ Categories based on internationally-validated WHO AUDIT guidelines

e As perceived and reported by TW participants

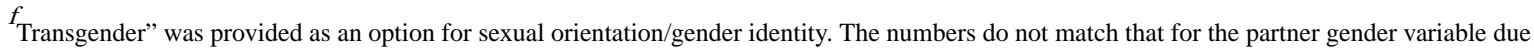
to presence of other options for classifying partner sexual behaviors.

$g_{\text {"Other" qualitative responses included: macho, bisexual }}$ 